\title{
PERILAKU PEMBELIAN MEREK FAST FASHION PADA GENERASI MILENIAL DI INDONESIA
}

\author{
PURCHASE BEHAVIOR OF FAST FASHION BRAND ON THE MILLENIAL GENERATION IN INDONESIA
}

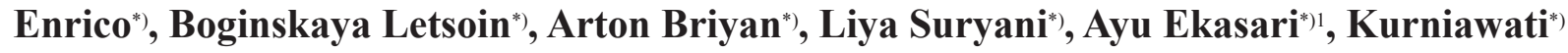 \\ ${ }^{*}$ Universitas Trisakti, Jakarta \\ Jl. Kyai Tapa No.1, Grogol Jakarta 11440, Indonesia
}

\begin{abstract}
The purpose of this study is to analyze millennial buying behavior towards world fast fashion brands in Indonesia. The total number of respondents in the research that could be processed was 188 respondents. The criteria for respondents are the millennial generation in Indonesia who bought Zara, $H \& M$ and Uniqlo brand products. The data analysis of this study used LISREL 8.80. The results of this study have a positive effect on brand awareness and store atmosphere and the hypothesis is supported on millennials' purchasing behavior; brand nationality and brand consciousness have a negative effect and the hypothesis is not supported on millennials' purchasing behavior; brand consciousness and brand nationality have a positive influence and the hypothesis is supported on brand awareness; brand awareness has a mediating role and the hypothesis is supported between brand consciousness and brand nationality on millennials' purchasing behavior; Brand schematicity does not have a moderating role and the hypothesis is not supported by brand awareness, brand consciousness and brand nationality on millennials' purchasing behavior. The implication of this research is that fast fashion brands can increase brand awareness and store atmosphere to maximize the potential opportunities for fast fashion brands to millennials' purchasing behavior.
\end{abstract}

Keywords: brand awareness, brand consciousness, brand nationality, brand schematicity, store atmosphere

\begin{abstract}
Abstrak: Tujuan dari penelitian ini adalah menganalisis perilaku pembelian milenial terhadap merek fast fashion dunia yang ada di Indonesia. Total responden pada penelitian yang dapat diolah sebanyak 188 responden. Kriteria responden adalah generasi milenial di Indonesia yang membeli produk merek Zara, H\&M dan Uniqlo. Analisis data penelitian ini menggunakan LISREL 8.80. Hasil penelitian ini adalah brand awareness dan store atmosphere berpengaruh positif dan hipotesisnya didukung terhadap millennials' purchasing behavior; brand nationality dan brand consciousness memiliki pengaruh negatif dan hipotesisnya tidak didukung terhadap millennials' purchasing behavior; brand consciousness dan brand nationality memiliki pengaruh positif dan hipotesisnya didukung terhadap brand awareness; brand awareness memiliki peran mediasi dan hipotesisnya didukung antara brand consciousness serta brand nationality terhadap millennials' purchasing behavior; brand schematicity tidak memiliki peran moderasi dan hipotesisnya tidak didukung kepada brand awareness, brand consciousness dan brand nationality terhadap millennials' purchasing behavior. Implikasi penelitian ini adalah merek fast fashion dapat meningkatkan brand awareness serta store atmosphere untuk memaksimalkan potensi peluang merek fast fashion terhadap millennials' purchasing behavior.
\end{abstract}

Kata kunci: brand awareness, brand consciousness, brand nationality, brand schematicity, store atmosphere

\footnotetext{
${ }^{1}$ Corresponding author:

Email: ayu.ekasari@trisakti.ac.id
} 


\section{PENDAHULUAN}

Istilah generasi milenial mengacu pada orang-orang yang lahir dari tahun 1980-2000 (Naumovska, 2017). Di Indonesia, ada sekitar 90 juta milenial yang merupakan $33,75 \%$ dari total populasi penduduk di Indonesia (Sembiring, 2018; Susanti, 2020). Generasi milenial cenderung berfokus pada pembentukan citra pribadi dan membeli barang untuk penggunaan pribadi mereka. Generasi milenial memiliki tingkat kesadaran yang tinggi tentang pentingnya membeli suatu barang karena keinginan mereka untuk membentuk citra pribadi (Wiangga, 2016; Edelman dan StrategyOne, 2010; Ainunnisa, 2016). Kecenderungan inilah yang mempengaruhi banyak pengusaha di industri fashion di Indonesia (Leman et al. 2020). Kecenderungan pola konsumtif dan perubahan tren yang berubah dengan cepat menyebabkan munculnya konsep ready to wear yaitu fast fashion (Leman et al. 2020). Fast fashion dideskripsikan sebagai koleksi busana murah yang mengikuti tren serta waktu produksi yang cepat (Debrilian dan Muslichah, 2018). Survei menempatkan Zara, $H \& M$ dan Uniqlo pada urutan kedua, keempat, dan ketujuh merek fast fashion yang diminati di seluruh dunia (Finance, 2019). Ketiga merek fast fashion ini merupakan merek yang paling digemari di Indonesia (Arman, 2020).

Di sisi lain, perkembangan industri fashion di Indonesia mampu berkontribusi sekitar 18,01\% atau Rp 116 triliun (CNBC, 2019), termasuk di dalamnya fast fashion. Persaingan antar merek fast fashion yaitu Zara, H\&M dan Uniqlo semakin ketat, sehingga pemilik merek harus mengetahui faktor-faktor yang mendorong generasi milenial memilih merek mereka agar bisa bertahan dalam industri fashion. Dengan mengetahui faktor-faktor tersebut, pemilik merek fast fashion dapat merancang strategi pemasaran yang tepat. Dalam hal ini konsep brand menjadi penting sebagai daya tarik dalam keputusan pembelian konsumen. Konsep brand yang dimaksud yaitu seperti brand awareness, brand consciousness, brand nationality dan brand schematicity (Rahman et al. 2020). Brand awareness adalah kemampuan konsumen untuk mengingat suatu merek pada kategori produk tertentu (Ramadayanti, 2019; Chandra dan Keni, 2019). Brand consciousness merupakan ekspresi konsumen terhadap kesadaran merek yang menandakan status dengan memiliki merek-merek mewah (Sharda dan Bhat, 2018). Brand nationality yaitu branding bangsa yang tercemin melalui citra, nilai dan identitasnya sehingga konsumen membangun persepsi positif terhadap negara tersebut (Sataøen, 2019). Brand schematicity adalah representasi konsumen yang cenderung memproses informasi sesuai dengan skema merek, seperti orang yang dikategorikan dalam ras atau skema gender (Grewal, 2012).

Disamping konsep brand yang berpengaruh terhadap keputusan pembelian fashion, ada faktor lain yang memiliki pengaruh terhadap keputusan pembelian yaitu store atmosphere (Muruganantham dan Bhakat, 2013), karena merek-merek tersebut dijual di store. Store atmosphere suatu outlet sangat penting dalam memberikan kesan positif sehingga konsumen merasa nyaman dan tertarik (Wijaya, 2019). Store atmosphere adalah suasana karakteristik fisik eksterior dan interior dari sebuah ruang yang membentuk citra (Tansala et al. 2019). Store atmosphere adalah faktor penting dalam meningkatkan niat pembelian impulsif (Karbasivar dan Yarahmadi, 2011); (Dewi dan Giantari, 2015). Hasil dari penelitian mengenai faktor-faktor yang mempengaruhi pembelian generasi milenial diharapkan dapat memberikan umpan balik. Hal ini berguna untuk meningkatkan penjualan serta menemukan solusi dan inovasi untuk perusahaan sehingga mereka dapat memperoleh keuntungan yang diharapkan.

Kebaruan dari penelitian ini adalah menggabungkan konsep brand dengan store atmosphere yang sejauh pengetahuan peneliti, belum ada penelitian yang menggabungkan kedua konsep tersebut. Penelitian ini melakukan analisis mengenai pengaruh pembelian produk fast fashion terhadap variabel store atmosphere yang dianggap dapat meningkatkan niat dalam membeli produk fast fashion.

Penelitian ini memiliki dua tujuan. Tujuan yang pertama yaitu mengembangkan konseptual baru yang menggabungkan faktor tangible dan intangible untuk memprediksi perilaku pembelian generasi milenial dalam memutuskan untuk membeli fast fashion. Tujuan kedua adalah memberikan masukan kepada pemilik merek fast fashion agar dapat merancang strategi pemasaran yang tepat. 


\section{METODE PENELITIAN}

Penelitian ini dilakukan di Indonesia pada bulan Oktober hingga November 2020. Penelitian ini menggunakan data cross-sectional yang mengamati suatu fenomena pada waktu tertentu. Sumber data pada penelitian ini yaitu data primer yang didapatkan melalui metode survei dan data sekunder yang diperoleh secara tidak langsung melalui buku, website dan jurnal sebagai pendukung data primer dalam penelitian.

Penelitian ini dilakukan dengan menggunakan non probability sampling dengan teknik purposive sampling (Sekaran dan Bougie, 2016). Kriteria sampel adalah konsumen milenial yang telah membeli produk fast fashion merek Zara, H\&M dan Uniqlo minimal 2 kali dalam 2 tahun terakhir. Sesuai dengan (Joseph F et al. 2010), jumlah responden sebanyak 10 dikalikan jumlah indikator. Setelah dilakukan screening terhadap 230 jawaban yang masuk, hanya 188 yang memenuhi syarat. Data kriteria responden dapat dilihat pada Tabel 1.

Tabel 1. Demografi Responden

\begin{tabular}{lcc}
\hline Kriteria & Total & Presentase \\
\hline Gender & 64 & $34 \%$ \\
Pria & 124 & $66 \%$ \\
Wanita & & \\
Usia & 135 & $72 \%$ \\
$20-29$ & 53 & $28 \%$ \\
$30-39$ & & \\
Domisili & 81 & $43 \%$ \\
DKI Jakarta & 58 & $31 \%$ \\
Jawa Barat & 19 & $10 \%$ \\
Banten & 22 & $12 \%$ \\
Jawa Timur & 2 & $1 \%$ \\
Jawa Tengah & 2 & $1 \%$ \\
Aceh & 1 & $0,5 \%$ \\
Sulawesi Utara & 1 & $0,5 \%$ \\
Sumatera Utara & 1 & $0,5 \%$ \\
Papua & 1 & $0,5 \%$ \\
Lampung & & \\
Frekuensi Pembelian & 68 & $36 \%$ \\
$2-3$ kali & 120 & $64 \%$ \\
$>4$ kali & &
\end{tabular}

Penelitian ini menggunakan Structural Equation Modeling untuk menganalisis data dengan bantuan software LISREL 8.80. Dipilihnya SEM sebagai metode analisa data karena rerangka konseptual yang rumit dan tidak memungkinkan untuk menggunakan analisa regresi biasa.

Peneliti juga melakukan uji goodness of fit model test yang digunakan untuk mengukur kesesuaian model yang akan digunakan dalam penelitian (Joseph et al. 2010). Hasil uji goodness of fit model test penelitian dapat dilihat pada Tabel 2. Hasil uji goodness of fit dapat dinyatakan bahwa model penelitian dinyatakan goodness of fit karena dilihat dari nilai RMSEA dinyatakan good fit dan nilai RFI, NFI, dan CFI dinyatakan good fit yang menyatakan bahwa model tersebut telah lolos uji dan dapat masuk ke dalam tahap uji selanjutnya.

Variabel penelitian ini diadopsi dari penelitian (Rahman et al. 2020) dan (Dewi and Giantari, 2015). Sedangkan instrumen penelitian diadopsi dari : (1) brand awareness (Yoo dan Donthu, 2001); (2) brand consciousness (Giovannini et al. 2015); (3) brand nationality (Mohd et al. 2007); (4) brand schematicity (Lia Zarantonello and Pauwels-Delassus, 1992); (5) millennial's purchase behaviour (Caruana, 2002); (6) store atmosphere (Yoon, 2013; Dewi dan Giantari, 2015; Wijaya, 2019).

Pemberian skor kuisioner penelitian ini menggunakan skala Likert lima poin (Sekaran dan Bougie, 2016). Penggunaan skala Likert lima poin mengacu pada penelitian Rahman et al. (2020). Indikator dalam penelitian ini sebanyak 35 pernyataan tetapi hanya 23 pernyataan yang dapat digunakan setelah dilakukan uji validitas. Uji validitas dilakukan untuk melihat apakah instrumen yang digunakan benar - benar mengukur variabel yang akan diukur. Pada penelitian ini, jika nilai Factor Loading $>$ 0,5 menunjukkan bahwa instrumen tersebut valid untuk digunakan. Uji Reliabilitas diukur menggunakan nilai Construct Reliability (CR) dengan nilai minimal 0,7 . Hasil uji validitas dan reliabilitas pada penelitian ini dapat dilihat pada Tabel 3 . 
Tabel 2. Hasil Goodness of Fit Test

\begin{tabular}{lcc}
\hline Ukuran Goodness of Fit & Target Kecocokan & Keterangan \\
\hline Normal Theory Weighted Least Squares Chi-Square $=1,61(\mathrm{P}=0,446)$ & $\mathrm{P}$ Value $>0,05$ & Good Fit \\
RMSEA $=0,000$ & $<0,05$ atau & Good Fit \\
& $0,05 \leq$ RMSEA $<0,08$ & \\
NFI $=0,99$ & $\geq 0,90$ & Good Fit \\
NNFI $=1,00$ & $\geq 0,90$ & Good Fit \\
CFI $=1,00$ & $\geq 0,90$ & Good Fit \\
IFI $=1,00$ & $\geq 0,90$ & Good Fit \\
RFI $=0,97$ & $\geq 0,90$ & Good Fit \\
RMR $=0,012$ & $\leq 0,10$ & Good Fit \\
Standardized RMR $=0,012$ & $\leq 0,10$ & Good Fit \\
GFI $=1,00$ & $\geq 0,90$ & Good Fit \\
AGFI $=0,97$ & $0,80 \leq \mathrm{AGFI}<0,90$ & Good Fit \\
\hline
\end{tabular}

Tabel 3. Hasil uji validitas dan reliabilitas

\begin{tabular}{|c|c|c|c|}
\hline $\begin{array}{l}\text { First Order } \\
\text { Construct }\end{array}$ & Item & $\begin{array}{c}\text { Factor } \\
\text { Loading } \\
(>0,5)\end{array}$ & $\begin{array}{c}\mathrm{CR} \\
(>0,7)\end{array}$ \\
\hline \multirow{3}{*}{$\begin{array}{l}\text { Brand } \\
\text { Awareness }\end{array}$} & Saya dapat mengenali merek pakaian fashion saya di antara merek pesaing lainnya. & 0,720 & 0,799 \\
\hline & $\begin{array}{l}\text { Beberapa karakteristik merek pakaian fashion saya muncul di benak saya dengan } \\
\text { cepat. }\end{array}$ & 0,720 & \\
\hline & Saya dengan cepat mengingat atribut merek pakaian fashion saya. & 0,580 & \\
\hline \multirow{5}{*}{$\begin{array}{l}\text { Brand } \\
\text { Consciousness }\end{array}$} & Saya memperhatikan nama merek fashion yang saya beli. & 0,520 & 0,754 \\
\hline & Nama-nama merek memberi tahu saya tentang betapa "keren" suatu item pakaian. & 0,710 & \\
\hline & $\begin{array}{l}\text { Terkadang saya bersedia membayar lebih banyak uang untuk pakaian karena nama } \\
\text { mereknya. }\end{array}$ & 0,710 & \\
\hline & Pakaian bermerek yang harganya mahal adalah kualitas yang baik. & 0,520 & \\
\hline & Saya memperhatikan nama merek dari sebagian besar produk yang saya beli. & 0,500 & \\
\hline \multirow[t]{4}{*}{$\begin{array}{l}\text { Brand } \\
\text { Nationality }\end{array}$} & $\begin{array}{l}\text { Asal negara merek fashion clothing adalah negara dengan tingkat kemajuan } \\
\text { teknologi. }\end{array}$ & 0,550 & 0,767 \\
\hline & Asal negara merek fashion clothing adalah negara yang pandai dalam mendesain. & 0,720 & \\
\hline & Asal negara merek fashion clothing adalah negara kreatif pengerjaannya. & 0,630 & \\
\hline & Negara asal merek fashion clothing adalah negara bergengsi. & 0,640 & \\
\hline \multirow[t]{4}{*}{$\begin{array}{l}\text { Brand } \\
\text { Schematicity }\end{array}$} & $\begin{array}{l}\text { Atribut merek pakaian fashion lebih penting daripada nama merek fashion dalam } \\
\text { keputusan pembelian saya. }\end{array}$ & 0,740 & 0,769 \\
\hline & Merek fashion sama sekali tidak penting bagi saya. & 0,500 & \\
\hline & Saya suka menggunakan merek pakaian fashion terkenal di rumah untuk diri saya. & 0,500 & \\
\hline & $\begin{array}{l}\text { Nama merek fashion adalah informasi yang paling tidak penting bagi saya ketika } \\
\text { saya mempertimbangkan suatu produk. }\end{array}$ & 0,710 & \\
\hline \multirow{3}{*}{$\begin{array}{l}\text { Millennials' } \\
\text { Purchasing } \\
\text { Behavior }\end{array}$} & $\begin{array}{l}\text { Saya telah membeli pakaian merek fashion ini lebih banyak daripada merek fashion } \\
\text { lainnya selama beberapa tahun terakhir. }\end{array}$ & 0,790 & 0,843 \\
\hline & Saya menganggap merek pakaian fashion ini sebagai merek fashion utama saya. & 0,870 & \\
\hline & $\begin{array}{l}\text { Merek pakaian fashion ini telah menjadi merek fashion utama saya selama beberapa } \\
\text { tahun terakhir. }\end{array}$ & 0,920 & \\
\hline \multirow{4}{*}{$\begin{array}{l}\text { Store } \\
\text { Atmosphere }\end{array}$} & Saya merasa nyaman dengan aroma store. & 0,790 & 0,810 \\
\hline & Store terlihat bersih dan menarik. & 0,870 & \\
\hline & Saya merasa nyaman dengan sirkulasi udara dalam store. & 0,920 & \\
\hline & Suhu ruangan store sejuk. & 0,620 & \\
\hline
\end{tabular}


Pada penelitian sebelumnya ditemukan bahwa: (1) Brand awareness mempunyai pengaruh yang signifikan terhadap keputusan dan perilaku pembelian (Ramadayanti, 2019; Rahman et al. 2020); (2) Brand consciousness diidentifikasi memiliki pengaruh positif terhadap perilaku pembelian konsumen (Gan et al. 2008; Jadhav dan Khanna, 2016; Rahman et al. 2020); (3) Brand nationality dengan citra produk yang disukai memiliki efek langsung pada kepercayaan konsumen dan dapat mempengaruhi perilaku pembelian konsumen (Chang dan Fan, 2017; Rahman et al. 2020); (4) Semakin tinggi brand consciousness dan brand nationality maka semakin tinggi brand awareness terhadap produk fashion (Rahman et al. 2020); (5) Brand awareness memiliki peran mediasi terhadap perilaku dan niat membeli suatu produk (Sharifi, 2014; Rahman et al. 2020); (6) Brand schematicity memiliki peran moderasi dalam perilaku pembelian konsumen (Carsana dan Jolibert, 2017; Rahman et al. 2020) dan (7) Store atmosphere dapat memberikan kesan positif dan meningkatkan timbulnya pembelian impulsive (Karbasivar dan Yarahmadi, 2011; Dewi dan Giantari, 2015; Wijaya, 2019). Berdasarkan uraian penjelasan hasil penelitian sebelumnya, maka kerangka penelitian yang dikembangkan dalam penelitian pada Gambar 1.
Hipotesis penelitian ini adalah (1) Brand awareness secara positif mempengaruhi millennials' purchasing behavior; (2) Brand consciousness secara positif mempengaruhi brand awareness (3) Brand consciousness secara positif mempengaruhi millennials' purchasing behavior, (4)Brand nationality secara positif mempengaruhi brand awareness; (5) Brand nationality secara positif mempengaruhi millennials' purchasing behavior; (6) Brand awareness memediasi hubungan antara brand consciousness terhadap millennials' purchasing behavior; (7) Brand awareness memediasi hubungan antara brand nationality terhadap millennials' purchasing behavior; (8) Brand schematicity memiliki peran moderasi hubungan antara brand consciousness terhadap millennials' purchasing behavior; (9) Brand schematicity memiliki peran moderasi hubungan antara brand awareness terhadap millennials' purchasing behavior; (10) Brand schematicity memiliki peran moderasi hubungan antara brand nationality terhadap millennials 'purchasing behavior; (11) Store atmosphere memiliki pengaruh terhadap millennials' purchasing behavior.

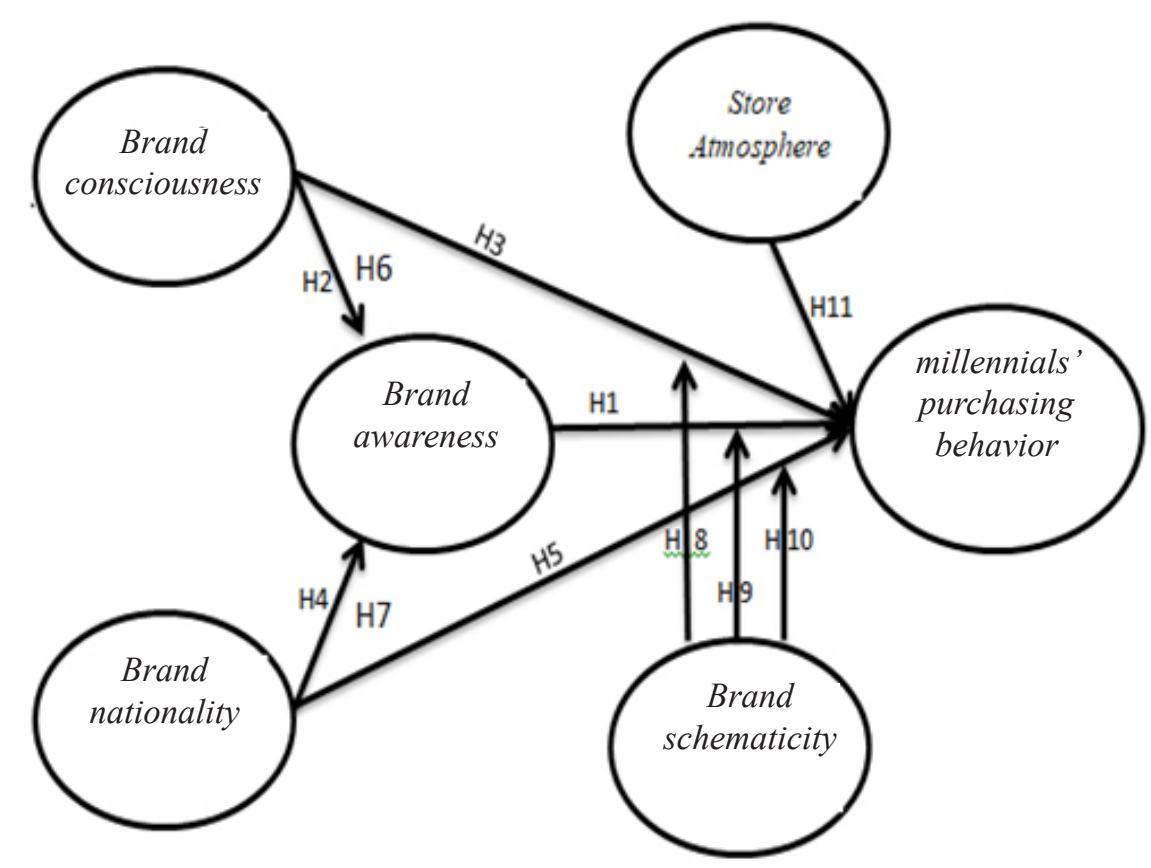

Gambar 1. Kerangka pemikiran penelitian 


\section{HASIL}

Jika nilai T value $>1,96$ artinya hipotesis didukung dan memiliki peran positif. Hasil Uji Hipotesis (Tabel 4), hipotesis penelitian yang didukung dan memiliki peran signifikan adalah hipotesis $\mathrm{H} 1, \mathrm{H} 2, \mathrm{H} 4, \mathrm{H} 6, \mathrm{H} 7$ dan H11. Hasil uji H1 ditemukan bahwa brand awareness memiliki pengaruh positif terhadap millennials" purchasing behavior. Hal ini membuktikan bahwa merek fast fashion Zara, H\&M dan Uniqlo mampu menciptakan brand awareness terhadap konsumen milenial sehingga mereka dapat mengenali, mengingat atribut dan karakteristik merek pakaian fast fashion tersebut. Hasil ini sesuai dengan penelitian yang dilakukan oleh Ramadayanti (2019) dan Rahman et al. (2020).

Hasil uji pada H2 dimana brand consciousness memiliki pengaruh positif terhadap brand awareness dan hasil uji H4 dimana brand nationality memiliki pengaruh positif terhadap brand awareness. Hasil ini sesuai dengan penelitian Rahman et al. (2020) dimana semakin tinggi brand consciousness dan brand nationality maka semakin tinggi brand awareness terhadap produk fashion.

Pada H6 dan H7 dimana brand awareness terbukti memiliki peran mediasi yang positif terhadap millennials' purchasing behavior. Hasil ini menunjukkan bahwa brand awareness mampu memediasi brand consciousness dan brand nationality. Brand consciousness dan brand nationality dari ketiga merek fast fashion mampu memberikan pengetahuan dan menanamkan brand awareness dari konsumen. Hasil ini sesuai dengan penelitian (Sharifi, 2014; Rahman et al. 2020) dimana brand awareness memiliki peran mediasi terhadap perilaku dan niat membeli suatu produk.

Tabel 4. Hasil uji hipotesis

\begin{tabular}{lcc}
\hline Hipotesis & Nilai T (> 1,96) & Keputusan \\
\hline $\begin{array}{l}\text { H1: Brand awareness secara positif mempengaruhi millennials' purchasing } \\
\text { behavior. }\end{array}$ & 16,69 & H1: Didukung \\
$\begin{array}{l}\text { H2: Brand consciousness secara positif mempengaruhi Brand awareness. } \\
\text { H3: Brand consciousness secara positif mempengaruhi millennials' }\end{array}$ & 4,29 & H2: Didukung \\
purchasing behavior. & 0,69 & H3: Tidak Didukung \\
$\begin{array}{l}\text { H4:Brand nationality secara positif mempengaruhi Brand awareness. } \\
\text { H5: Brand nationality secara positif mempengaruhi millennials'purchasing } \\
\text { behavior. }\end{array}$ & 3,54 & H4: Didukung \\
$\begin{array}{l}\text { H6: Brand awareness memediasi hubungan antara brand consciousness dan } \\
\text { millennials' purchasing behavior. }\end{array}$ & 16,69 & H5: Tidak Didukung \\
$\begin{array}{l}\text { H7: Brand awareness memediasi hubungan antara brand nationality dan } \\
\text { millennials' purchasing behavior. }\end{array}$ & 16,69 & H6: Didukung \\
$\begin{array}{l}\text { H8: Brand schematicity memiliki peran moderasi hubungan antara brand } \\
\text { consciousness terhadap millennials' purchasing behavior. }\end{array}$ & 0,65 & H7: Didukung \\
$\begin{array}{l}\text { H9: Brand schematicity memiliki peran moderasi hubungan antara brand } \\
\text { awarenss terhadap millennials'purchasing behavior. }\end{array}$ & $(1,16)$ & H9: Tidak Didukung \\
$\begin{array}{l}\text { H10: Brand schematicity memiliki peran moderasi hubungan antara brand } \\
\text { nationality terhadap millennials' purchasing behavior. }\end{array}$ & 0,12 & H10: Tidak Didukung \\
$\begin{array}{l}\text { H11: Store atmosphere memiliki pengaruh positif terhadap pada millennials' } \\
\text { purchasing behavior. }\end{array}$ & 250,82 & H11: Didukung \\
\hline
\end{tabular}


Hasil uji H11 ditemukan bahwa store atmosphere memiliki pengaruh positif terhadap millennials, purchasing behavior. Store atmosphere dapat memberikan kesan positif dan meningkatkan timbulnya pembelian impulsive, hasil ini sesuai dengan hasil penelitian yang dilakukan oleh (Karbasivar dan Yarahmadi, 2011; Dewi and Giantari, 2015; Wijaya, 2019).

Hipotesis yang tidak didukung dan tidak memiliki peran signifikan pada penelitian ini adalah $\mathrm{H} 3, \mathrm{H} 5, \mathrm{H} 8, \mathrm{H} 9$ dan H10. Pada hasil uji H3 ditemukan bahwa tidak ada pengaruh brand consciousness terhadap millennials' purchasing behavior. Hasil ini menunjukkan, meskipun konsumen consciousness pada barang populer tidak berarti dapat mendorong niat beli konsumen. Hasil ini sesuai dengan penelitian sebelumnya yang dilakukan Lee (2008) dan Soh et al. (2017). Brand consciousness tidak memiliki pengaruh direct terhadap niat beli. Hal ini diduga adanya variabel perantara untuk meningkatkan niat beli seperti kualitas dan harga (Lee et al. 2012; Kautish et al. 2020). Peran variabel perantara juga dapat dilihat pada hasil penelitian ini dimana brand awareness sebagai mediator dapat berpengaruh pada brand consciousness terhadap millennials'purchasing behavior.

Hasil uji H5 ditemukan bahwa brand nationality tidak memiliki pengaruh terhadap millennials' purchasing behavior. Walaupun konsumen mengetahui produk tersebut berasal dari negara yang bergengsi, tingkat kemajuan teknologi yang tinggi dan kreatif tidak menjadikan indikator tersebut sebagai acuan saat membeli sebuah produk. Hal ini serupa dengan penelitian sebelumnya, konsumen mempertimbangkan faktor lain seperti harga yang murah dibandingkan informasi mengenai negara asal merek (Tati et al. 2015). Faktor variabel mediator seperti brand awareness pada penelitian ini terbukti dapat memediasi hubungan antara brand nationality terhadap millennials' purchasing behavior.

Hasil uji H8, H9 dan H10 menunjukkan bahwa brand schematicity tidak memiliki peran moderasi antara brand awareness, brand nationality dan brand consciousness terhadap millennials' purchasing behavior. Nilai $\mathrm{T}$ value dari hasil uji $\mathrm{H} 8=0,65 ; \mathrm{H} 9$ $=(1,16)$ dan $\mathrm{H} 10=0,12$ kurang dari 1,96. Hal ini menunjukkan tidak ada peran moderasi karena nilai $\mathrm{T}<1,96$. Hasil ini berbeda dengan hasil penelitian terdahulu dari Carsana dan Jolibert (2017) dan Rahman et al. (2020) dimana brand schematicity memiliki peran moderasi terhadap millennials' purchasing behavior. Hal ini dapat membuktikan bahwa generasi milenial memiliki tingkat brand schematicity yang rendah. Sehingga brand schematicity bukan faktor pendorong dalam niat belanja dan dapat dikatakan salah satu faktor pendorong niat belanja adalah social influence (Piarna, 2020).

\section{Implikasi Manajerial}

Berdasarkan kesimpulan tersebut, maka implikasi manajerial yang bisa disarankan kepada pemilik merek fast fashion adalah: memaksimalkan komunikasi pemasaran melalui berbagai cara untuk meningkatkan brand awareness konsumen akan keberadaan merek. Oleh karena generasi milenial adalah pengguna teknologi informasi dan gadget terutama di kelompok usia paling muda, maka pemanfaatan media sosial seperti Instagram, Twitter dan YouTube akan sangat tepat sasaran untuk meningkatkan brand awareness.

Di samping itu, pemilik merek fast fashion juga harus menonjolkan atribut yang dimilikinya sehingga konsumen dapat cepat mengenalinya dibandingkan merek lain. Atribut atau karakteristik yang diusung sebuah merek fast fashion seperti minimalis, kontemporermaupun klasik semestinya secara konsisten dijaga oleh merek tersebut dan dikomunikasikan kepada konsumen.

\section{KESIMPULAN DAN SARAN}

\section{Kesimpulan}

Kesimpulan pada penelitian ini adalah brand awareness dan store atmosphere adalah faktor - faktor penting yang dapat mendorong pembelian fast fashion oleh kaum milenial. Selain itu, store atmosphere tempat produk dijual juga perlu dirancang sedemikian rupa agar membuat konsumen nyaman, berlama-lama di toko dan akhirnya memutuskan membeli.

Beberapa aspek yang perlu dijadikan perhatian antara lain interior toko yang bisa dibuat up to date dan kontemporer, pencahayaan yang terang dan pemilihan warna cat dinding yang membuat konsumen merasa betah dan nyaman. Di samping itu, perlu juga diperdengarkan alunan musik yang menimbulkan mood positif bagi konsumen serta sirkulasi udara yang 
membuat toko terasa lapang. Selain itu, toko juga harus selalu tampil bersih dan rapi. Suasana toko yang berbeda dapat memberikan value tersendiri bagi konsumen.

\section{Saran}

Penelitian yang akan datang hendaknya mengakomodir variabel-variabel lain yang berpengaruh terhadap keputusan pembelian generasi milenial, sehingga diperoleh model penelitian yang lebih komprehensif. Peneliti selanjutnya juga diharapkan menggunakan merek fast fashion dalam negeri untuk mengetahui minat beli generasi milenial, sehingga merek dalam negeri bisa bersaing dengan merek dari luar negeri. Keterbatasan penelitian ini adalah hanya meneliti merek fast fashion yang berasal dari luar negeri. Padahal, Indonesia sendiri memiliki merek fast fashion yang juga digemari konsumen dengan kualitas dan harga yang setara dengan merek dari luar negeri.

\section{DAFTAR PUSTAKA}

Ainunnisa L. Perilaku konsumtif mahasiswa. https:// www.kompasiana.com/lainunnisa. [10 Oktober 2020].

Allis N. 2006. "Cross-sectional vs Longitudinal": Pilihan rancangan waktu dalam penelitian perumahan permukiman. DIMENSI (Jurnal Teknik Arsitektur) 34(1):52-58.

Arman. 2020. Toko baju fast fashion yang digemari tahun 2020. https://orderonline.id [10 Oktober 2020].

Carsana L, Jolibert A. 2017. The influence of brand schematicity on the importance of product cues: Self-purchasing versus gift-giving situations. Journal of Consumer Marketing 34(3):255-267.

Caruana A. 2002. Service loyalty the effects of service quality and the mediating role of customer satisfaction. European Journal of Marketing 36(7):811-828.

Chandra C, Keni. 2019. Pengaruh brand awareness, brand association, perceived quality, dan brand loyalty terhadap customer purchase decision. Jurnal Muara Ilmu Ekonomi dan Bisnis 3(1):176.

Chang SW, Fan SH. 2017. Cultivating the brandcustomer relationship in Facebook fan pages: A study of fast-fashion industry. International Journal of Retail and Distribution Management 45(3):253-270.
CNBC. 2019. Gairah industri fashion Indonesia. https:// www.cnbcindonesia.com. [10 Oktober 2020].

Debrilian VM, Muslichah I. 2018. Analisis faktorfaktor yang mempengaruhi loyalitas konsumen terhadap merek fast fashion di Indonesia. Universitas Islam Indonesia.

Dewi K, Giantari I. 2015. Peran emosi positif dalam memediasi store atmosphere terhadap pembelian impulsif (studi pada konsumen Matahari Department Store Duta Plaza Denpasar). E-Jurnal Manajemen Universitas Udayana 4(12):241-632.

Edelman and StrategyOne. 2010. The 8095 Exchange: Millennials, heir Actions Surrounding Brands, and the Dynamics of Reverberation.

Finance, B. 2019. Apparel 502019 The annual report on the world's most valuable and strongest apparel brands. pp. 37-60.

Gan C et al. 2008. Consumers purchasing behavior towards green products in New Zealand. Innovative Marketing 4(1):93-102.

Giovannini S, Xu Y, Thomas J. 2015. Luxury fashion consumption and Generation $\mathrm{Y}$ consumers: Self, brand consciousness, and consumption motivations. Journal of Fashion Marketing and Management 19(1):22-40.

Grewal, R. 2012. The consumer-brand relationship. https://news.smeal.psu.edu. [10 Oktober 2020].

Jadhav V, Khanna M. 2016. Factors influencing online buying behavior of college students: A qualitative analysis. Qualitative Report 21(1):1-15.

Joseph FHJ et al. 2010. Multivariate Data Analysis. Ed. ke-8. UK: Cengage Learning, EMEA.

Karbasivar A, Yarahmadi H. 2011. Evaluating effective factors on consumer impulse buying behavior. Asian Journal of Business Management Studies 2(4):174-181.

Kautish P, Khare A, Sharma R. 2020. Influence of values, brand consciousness and behavioral intentions in predicting luxury fashion consumption. Journal of Product and Brand Management 30(4):513531.

Lee C. 2008. The Effects of Price Consciousness, Brand Consciousness and Familiarity on Store Brand Purchase Intention. Management Review 27(July): 113-117.

Lee WJ, Phau I, Roy R. 2012. "Bonds" or "Calvin Klein" Down-under: Consumer ethnocentric and brand country origin effects towards men's underwear. Journal of Fashion Marketing and Management 17(1):65-84. 
Leman FM, Soelityowati, Purnomo J. 2020. Dampak Fast Fashion Terhadap Lingkungan. Di dalam: Desain Produk dan Bisnis Fesyen. Prosiding Seminar Nasional ENVISI 2020; Surabaya, 13 Maret 2020. Surabaya: Universitas Ciputra. hlm 128-136.

Lia Z, Pauwels-Delassus V. 1992. The Handbook of Brand Management. New York: Routledge.

Lidya JS. 2018. Bappenas: Jumlah milenial di Indonesia capai 90 juta orang. https://www.inews.id/ finance. [10 Oktober 2020].

Mohd NY, Nasser MN, and Mohamad O. 2007. Does image of country-of-origin matter to brand equity?. Journal of Product and Brand Management 16(1):38-48.

Muruganantham G, Bhakat RS. 2013. A review of impulse buying behavior. International Journal of Marketing Studies:5149-160.

Naumovska L. 2017. Marketing communication strategies for Generation Y - Millennials. Business Management and Strategy 8(1):123133.

Piarna R. 2020. Analisis faktor-faktor yang mempengaruhi niat belanja online. Jurnal Ilmiah Ilmu dan Teknologi Rekayasa 3:9-17.

Rahman MS et al. 2020. Millennials' purchasing behavior toward fashion clothing brands: influence of brand awareness and brand schematicity. Journal of Fashion Marketing and Management.

Ramadayanti F. 2019. Peran brand awereness terhadap keputusan pembelian produk. Jurnal Studi Manajemen dan Bisnis 6(2):111-116.

Sataøen HL. 2019. Sub-sector branding and nation branding: the case of higher education. Corporate Communications: An International Journal 24(3):425-438.

Sharda N, Bhat AK. 2018. Austerity to materialism and brand consciousness: Luxury consumption in India. Journal of Fashion Marketing and Management 22(2):223-239.
Sekaran U, Bougie R. 2016. Research Methods for Business. Ed. ke-7. United Kingdom: John Wiley and Sons.

Sharifi SS. 2014. Impacts of the trilogy of emotion on future purchase intentions in products of high involvement under the mediating role of brand awareness. European Business Review 26(1):4363.

Soh CQY, Rezaei S, Gu ML. 2017. A structural model of the antecedents and consequences of Generation Y luxury fashion goods purchase decisions. Journal Young Consumer 18(2):180-204.

Susanti. 2020. Sensus penduduk 2020, sensus era digital. https://bandungkota.bps.go.id. [10 Oktober 2020].

Tansala D, Tumbel TM, Walangitan OFC. 2019. Pengaruh store atmosphere terhadap keputusan pembelian. Jurnal Administrasi Bisnis (JAB) $8(1): 21-27$.

Tati PW, Suharyono, Yulianto E. 2015. Pengaruh country of origin dan global brand image terhadap minat beli dan keputusan pembelian (survei pada konsumen yang membeli smartphone Samsung Galaxy di Asia Tenggara). Jurnal Administrasi Bisnis (JAB) 5(1): 1-10.

Wiangga LS. 2016. SEKTOR Ritel: Dominasi belanja konsumen, generasi millenial mulai disebut. Siapa mereka?. https://ekonomi.bisnis.com. [10 Oktober 2020].

Wijaya HS. 2019. Pengaruh customer perceived value, brand awareness, dan store atmosphere terhadap customer purchae intention Koi The Bubble Tea. Agora 7(2).

Yoo B, Donthu N. 2001. Developing and validating a multidimensional consumer-based brand equity scale. Journal of Business Research 52(1): $1-14$.

Yoon SJ. 2013. Antecedents and consequences of in-store experiences based on an experiential typology. European Journal of Marketing 47(5):693-714. 